\title{
Grão de Aveia Preta em Substituição ao Grão de Sorgo para Alimentação de Novilhos na Fase de Terminação 1
}

\section{Cristian Faturi ${ }^{2}$, João Restle ${ }^{3}$, Ivan Luiz Brondani ${ }^{4}$, Dari Celestino Alves Filho ${ }^{4}$, Joilmaro Rodrigo Pereira Rosa ${ }^{5}$, Fernando Kuss ${ }^{6}$, Luis Fernando Glasenapp de Menezes ${ }^{6}$}

\begin{abstract}
RESUMO - Foi estudado o efeito de quatro níveis de substituição ( $0 ; 33 ; 66$ e 100\%) do grão de sorgo (Sorghum bicolorL. Moench) por grão de aveia preta (Avena strigosa) na fração concentrado da dieta de novilhos, na fase de terminação em confinamento. Os novilhos, com idade média inicial de 19 meses e peso inicial de $381 \mathrm{~kg}$, foram alimentados com dieta composta por $60 \%$ de volumoso e $40 \%$ de concentrado, contendo PB para ganho de peso de $1,2 \mathrm{~kg} /$ animal/dia. No período de adaptação de sete dias e na primeira metade do período experimental (35 dias), o volumoso utilizado foi a silagem de sorgo forrageiro (Sorghum bicolor L. Moench) e na segunda metade do período experimental (32 dias), a silagem de milho (Zea mays). Durante o período de adaptação, as dietas com maior concentração de aveia promoveram melhor desempenho animal, no entanto, durante o período experimental, o aumento da proporção de aveia no concentrado, em substituição ao grão de sorgo, promoveu decréscimo linear no ganho de peso $(1,292 ; 1,251 ; 1,217$; e $1,051 \mathrm{~kg}$, respectivamente, para os níveis $0 ; 33 ; 66$ e 100\% de aveia), assim como aumentou linearmente a quantidade de alimento consumido para cada kg de peso vivo ganho $(7,911 ; 8,000 ; 8,220$ e 9,212 kg, respectivamente). O decréscimo no ganho de peso, à medida que aumentou o nível de aveia, esteve relacionado à maior concentração de FDN (29,3 vs 16,1\%) e menor concentração de energia digestível (3,179 vs 3,590 Mcal/kg) da aveia em relação ao sorgo, o que limitou o consumo de matéria seca e de energia digestível/animal/dia. A utilização de um volumoso de melhor qualidade no período final do confinamento, proporcionando maior consumo de matéria seca e de energia digestível, permitiu a uniformidade do ganho de peso durante todo o período experimental.
\end{abstract}

Palavras-chave: confinamento, energia digestível, FDN, ganho de peso, grão de aveia preta, grão de sorgo

\section{Replacement of Sorghum by Oat Grain for Finishing Steers}

\begin{abstract}
The effect of four levels (0;33; 66 and 100\%) of substitution of sorghum grain (Sorghum bicolor L. Moench) by oats grain (Avena strigosa) in the concentrate of diets for feedlot finishing steers, was studied. Steers (19 months old and initial weight of $381 \mathrm{~kg}$ ) were fed a diet containing $60 \%$ roughage and $40 \%$ concentrate, formulated for ADG of $1.2 \mathrm{~kg} / \mathrm{animal}$. During the adaptation period of seven days and in the first half of the experimental period (35 days) the roughage used was sorghum silage (Sorghum bicolor L. Moench) For the second half of the experimental period (32 days), the roughage used was corn silage (Zea mays). During the adaptation period, the diets with higher levels of oats promoted better animal performance, however, during the experimental period, the increase of oats proportion in the concentrate in substitution to sorghum grain resulted in a linear decrease of live weight gain (1.292; $1.251 ; 1.217$ and $1.051 \mathrm{~kg}$, respectively, for $0 ; 33 ; 66$ and $100 \%$ of oats), as well as linear increase in the amount of feed consumed per kg of live weight gain $(7.911 ; 8.000 ; 8.220$ and 9.212 , respectively). The decrease in live weight gain as the level of oats increased, was associated with the higher concentration of NDF (29.3 vs $16.1 \%$ ) and lower concentration of digestible energy (3.179 vs $3.590 \mathrm{Mcal} / \mathrm{kg}$ ) of oats compared to sorghum, which limited the dry matter intake and digestible energy intake/animal/day. The use of a roughage with better quality during the last half of the finishing period, provided uniformity of weight gain during the whole feedlot period, as a result of higher dry matter intake and digestible energy intake.
\end{abstract}

Key Words: digestible energy, feedlot, NDF, oat grain, sorghum grain, weight gain

\section{Introdução}

A adoção do confinamento no sistema de produção de ciclo completo, além de promover benefícios diretos ao sistema, como a redução na idade de abate através do ganho de peso dos animais no período de inverno, traz outros benefícios indiretos de grande valor para o sistema como um todo, sendo o principal a liberação de áreas de pastagens para outras categorias. O confinamento também permite que se pla-

\footnotetext{
1 Parte da Dissertação de Mestrado do primeiro autor.

2 Zootecnista, Aluno do curso de Pós-Graduação em Zootecnia da UFSM. E.mail: cfaturi@bol.com.br

3 Engㅇ-Agro, PhD, Professor Titular do Depto de Zootecnia da UFSM, Santa Maria, Camobi, CEP - 97105-900. E.mail: jorestle@ccr.ufsm.br

4 Engo-Agro, MS, Professor Assistente do Depto de Zootecnia da UFSM.

5 Engo-Agrö, Aluno do curso de Pós-Graduação em Zootecnia da UFSM.

6 Aluno do curso de Graduação em Zootecnia da UFSM.
} 
neje a data de abate dos animais, pois a terminação independe de fatores como a condição climática, uma vez que a forragem já está armazenada. Na Região Sul, o planejamento da data de abate é de grande importância, uma vez que ocorre variação no preço do $\mathrm{kg}$ do boi durante o ano, concentrando-se os maiores preços nos meses de agosto e setembro (ANUALPEC, 2000), que corresponde ao período de entressafra, pois neste período a maioria dos animais em pastagem cultivada ainda não está pronta para o abate.

Analisando os custos do confinamento, Restle \& Vaz (1999) verificaram que a alimentação é responsável por aproximadamente $70 \%$ do custo total do confinamento, sendo que desta fração cerca de $80 \%$ se refe re ao custo do alimento concentrado utilizado na dieta. Existem dversos alimentos concentrados que podem ser utilizados em formulações de dietas para confinamento, sendo classificados, de acordo com o nível de proteína bruta, em alimentos protéicos (acima de $20 \%$ de proteína bruta) e energéticos (menos de $20 \%$ de proteína bruta). No entanto, outras características também são relevantes na avaliação dos alimentos, como o teor de FDN, que, segundo Waldo (1986), é o fator melhor e mais simples para predizer o consumo voluntário de matéria seca por ruminantes; e o teor de energia digestível, sendo que a eficiência de utilização dos nutrientes da dieta para ganho de peso depende da concentração energética da dieta (NRC, 1984), da degradação ruminal (Martins et al., 1999), da taxa de passagem (Poore, et al., 1990), entre outras.

Estudar alimentos concentrados que propiciem um bom desempenho animal e apresentem, principalmente, baixo custo de aquisição, viabilizando a utilização do confinamento, é de suma importância para o produtor que, muitas vezes, tem em suas mãos produtos e/ou subprodutos da agricultura, mas não conhece o seu valor nutricional nem os efeitos sobre o desempenho animal. Nos últimos anos, principalmente no ano 2000, ocorreu grande oferta de aveia preta (Vaz et al. 2000), devido ao excedente de produção proveniente principalmente das Regiões das Missões e Planalto Médio, no Rio Grande do Sul, onde a aveia é cultivada para produção de grãos e sementes, bem como para formação de palhada necessária para o plantio direto das culturas de verão. Segundo Floss (2001), estima-se que no anode 2000 tenham sido cultivados no Rio Grande do Sul, de forma isolada ou consorciada, cerca de 1.250.000 ha de aveia. Este aumento de produção fez com que o preço do kg da aveia preta caísse, representando uma excelente opção para a alimentação animal, porém os trabalhos de pesquisa que demonstram o efeito da utilização do grão de aveia preta na dieta sobre o desempenho de bovinos de corte em confinamento são escassos em nossa literatura.

A utilização do grão de aveia foi estudada por Restle et al. (2001), que verificaram efeito significativo da forma de processamento do grão de aveia preta sobre o desempenho de vacas de descarte em confinamento. Estes autores observaram ganho de peso médio diário de $1,097 \mathrm{~kg}$, quando forneceram aos animais o grão de aveia preta na forma moída, e apenas $0,776 \mathrm{~kg}$, ao utilizarem o grão na forma inteira. Já Goi et al. (1998) não verificaram efeito da forma de processamento do grão de aveia branca (Avena sativa) sobre o desempenho animal, observando ganho de peso médio diário de 1,047; 1,055; 1,107; e $1,067 \mathrm{~kg}$, quando o grão de aveia foi fornecido aos animais, respectivamente, inteiro e seco, moído, na forma machacada e inteiro e umedecido. Alves Filho et al. (2001) compararam o grão de sorgo e o grão de aveia preta como suplemento para novilhos em pastagem cultivada e observaram que o grão de sorgo promoveu melhor desempenho dos animais em relação a aveia (1,262 vs 1,063 kg/animal/dia). Já Corah et al. (1973), na Austrália, utilizando novilhos com idade entre 18 e 20 meses, alimentados com grão de aveia inteiro e feno de azevém à vontade, observaram ganho de peso médio diário de 0,$53 ; 0,58$; 0,85 ; e $1,0 \mathrm{~kg}$, quando os animais receberam $0 ; 1,4$; 2,7; e 4,1 kg de grão de aveia, respectivamente.

O objetivo deste trabalho foi estudar a utilização do grão de aveia preta como alimento concentrado na alimentação de novilhos na fase de terminação em confinamento.

\section{Material e Métodos}

O experimento foi conduzido no Setor de Bovinocultura de Corte do Departamento de Zootecnia da Universidade Federal de Santa Maria, localizado no município de Santa Maria - RS, tendo como coordenadas $29^{\circ} 43^{\prime}$ 'de latitude Sul, e $53^{\circ} 42^{\prime}$ de longitude Oeste, e 149 metros de altitude. De acordo com a classificação de Köeppen, o clima predominante é o Cfa2, subtropical úmido com possibilidades de estiagem no verão, onde a temperatura média mensal máxima é superior a $22^{\circ} \mathrm{C}$ e a mínima varia entre $3 \mathrm{e} 18^{\circ} \mathrm{C}$. A precipitação média anual varia de 1300 a 1800 mm. 
Foram confinados, para terminação, 48 novilhos Charolês, Nelore e seus mestiços, tomados ao acaso do rebanho experimental do Departamento de Zootecnia, criados e recriados sob as mesmas condições de manejo e alimentação, com peso médio inicial de $381 \mathrm{~kg}$ e idade média inicial de 19 meses. Os animais foram divididos em 12 lotes, equilibrados por grupo genético, peso e estado corporal, sobre os quais foram sorteados os tratamentos, que eram constituídos por quatro níveis de substituição do grão de sorgo por grão de aveia preta no concentrado, assim identificados: $\mathrm{T} 0=$ concentrado com $100 \%$ de sorgo e $0 \%$ de aveia preta; $\mathrm{T} 33$ = concentrado com $66 \%$ de sorgo e $33 \%$ de aveia preta; T66 = concentrado com $33 \%$ de sorgo e $66 \%$ de aveia preta; $\mathrm{T} 100=$ concentrado com $0 \%$ de sorgo e $100 \%$ de aveia preta. Em todos os tratamentos, tanto o grão de aveia preta como o grão de sorgo foram moídos.

O período experimental foi subdivido em dois sub-períodos, o primeiro, de 35 dias, no qual os animais foram alimentados com silagem de sorgo forrageiro AG2002 como fonte de volumoso, e o segundo, de 32 dias, em que o volumoso foi a silagem de milho AG122. Utilizou-se silagem de sorgo forrageiro na primeira metade do período de confinamento, em razão de seu menor custo de produção, e silagem de milho para a segunda metade do período, devido à sua maior concentração energética, visando manter o mesmo ritmo de ganho de peso dos animais, já que estes necessitam de maior aporte energético em função da composição do ganho, à medida que atingem o grau de acabamento desejado.

Durante o período de confinamento, os animais foram alimentados ad libitum com uma dieta calculada, conforme NRC (1984), para fornecer proteína bruta suficiente para um ganho de peso de 1,2 kg por animal por dia. As composições dos concentrados estão apresentadas nas Tabelas 1 e 2 .

Os alimentos foram fornecidos duas vezes ao dia, sendo o concentrado misturado ao volumoso no cocho, no momento da alimentação, seguindo a relação volumoso:concentrado de 60:40. Na manhã do dia seguinte, foram coletadas, pesadas e descartadas as sobras de alimento para ajuste da quantidade ofertada e cálculo do consumo de matéria seca. As sobras foram mantidas entre 5 e $10 \%$ do total ofertado.

Durante o período experimental, foram recolhidas, semanalmente, amostras dos grãos de aveia, sorgo e silagens. Posteriormente, após a secagem em estufa, as amostras de cada alimento foram homogeneizadas e, após, retirada uma amostra composta para realização das análises laboratoriais. Foram determinados os teores de matéria seca e matéria orgânica, de proteína bruta e extrato etéreo (AOAC, 1970), a digestibilidade in vitro da matéria orgânica

Tabela 1 - Composição dos concentrados (\%) associados à silagem de sorgo, utilizados na alimentação dos novilhos na primeira metade do período de confinamento

Table 1 - Concentrates composition (\%) associated with sorghum silage, used for the feeding of the steers during the first half of the feedlot period

\begin{tabular}{lcccc}
\hline $\begin{array}{l}\text { Ingredientes } \\
\text { Ingredients }\end{array}$ & \multicolumn{4}{c}{$\begin{array}{c}\text { Concentrado (\% de aveia) } \\
\text { Concentrate (\% oat) }\end{array}$} \\
\cline { 2 - 5 } & 0 & 33 & 66 & 100 \\
\hline $\begin{array}{l}\text { Sorgo } \\
\text { Sorghum }\end{array}$ & 95,36 & 64,14 & 32,36 & - \\
$\begin{array}{l}\text { Aveia } \\
\text { Oat }\end{array}$ & - & 32,07 & 64,69 & 97,90 \\
$\begin{array}{l}\text { Uréia } \\
\text { Urea }\end{array}$ & 3,12 & 2,30 & 1,48 & 0,66 \\
$\begin{array}{l}\text { Calcário } \\
\text { Limestone }\end{array}$ & 1,02 & 0,99 & 0,97 & 0,95 \\
$\begin{array}{l}\text { Sal } \\
\text { Salt }\end{array}$ & 0,50 & 0,50 & 0,50 & 0,50 \\
$\begin{array}{l}\text { Ionóforo, g } \\
\text { Ionophore, } g\end{array}$ & 62 & 62 & 62 & 62 \\
\hline
\end{tabular}

*Monensina sódica.

Tabela 2 - Composição dos concentrados (\%) associados à silagem de milho, utilizados na alimentação dos novilhos na segunda metade do período de confinamento

Table 2 - Concentrates composition (\%) associated with corn silage, used for the feeding of the steers during the second half of the feedlot period

\begin{tabular}{lcccc}
\hline \multirow{2}{*}{$\begin{array}{l}\text { Ingredientes } \\
\text { Ingredients }\end{array}$} & \multicolumn{4}{c}{$\begin{array}{c}\text { Concentrado (\% de aveia) } \\
\text { Concentrate (\% oat) }\end{array}$} \\
\cline { 2 - 5 } & 0 & 33 & 66 & 100 \\
\hline $\begin{array}{l}\text { Sorgo } \\
\text { Sorghum }\end{array}$ & 96,27 & 64,75 & 32,66 & - \\
$\begin{array}{l}\text { Aveia } \\
\text { Oat }\end{array}$ & - & 32,38 & 65,31 & 98,83 \\
$\begin{array}{l}\text { Uréia } \\
\text { Urea }\end{array}$ & 2,49 & 1,66 & 0,84 & - \\
$\begin{array}{l}\text { Calcário } \\
\text { Limestone } \\
\text { Sal }\end{array}$ & 0,74 & 0,71 & 0,69 & 0,67 \\
$\begin{array}{l}\text { Salt } \\
\text { Ionóforo, g } \\
\text { Ionophore, } g\end{array}$ & 0,50 & 0,50 & 0,50 & 0,50 \\
* & & 60 & 60 & 60 \\
\hline
\end{tabular}

* Monensina sódica (Monensin). 
(Tilley \& Terry, 1963) e o teor de fibra em detergente neutro (FDN) (Van Soest, 1967). Para obtenção da concentração de energia digestível, utilizou-se a equação sugerida pelo ARC (1980) com base na digestibilidade da matéria orgânica.

Os animais foram alojados em 12 boxes pavimentados de $20 \mathrm{~m}^{2}$, em confinamento semicoberto, providos de comedouro e bebedouro. Os animais entraram no confinamento no dia 21 de maio, sendo submetidos à adaptação por uma semana e pesados no início e final do período de adaptação, bem como ao final de cada sub-período de alimentação. As pesagens ocorreram após jejum de sólidos de 14 horas.

O delineamento experimental utilizado foi o inteiramente casualizado, com quatro tratamentos (concentrados) e três repetições, sendo cada repetição composta por um lote de quatro animais. Os dados foram submetidos à análise de variância, testando-se os efeitos de tratamento (nível de aveia no concentrado), subperíodo alimentar (tipo de silagem) e a interação entre estes dois fatores. Para a comparação entre os tratamentos, foi utilizada a análise de regressão polinomial e para a comparação de médias entre os sub-períodos alimentares, o teste " $\mathrm{t}$ ". Todas as análises foram realizadas com o auxílio do programa estatístico SAS System (SAS, 1993), sendo descritas pelo seguinte modelo estatístico: $\tilde{\mathrm{O}}_{\mathrm{ikk}}=\grave{\mathrm{i}}+\hat{\mathrm{O}}_{\mathrm{i}}+\hat{e}_{\mathrm{k}}\left(\hat{\mathrm{O}}_{\mathrm{i}}\right)+\tilde{\mathrm{n}}_{\mathrm{i}}+(\hat{\mathrm{o} n ̃})_{\mathrm{ij}}+\stackrel{\circ}{\mathrm{ijk}}_{\mathrm{k}}$, em que: $\tilde{\mathrm{Q}}_{\mathrm{ik}}=$ variáveis dependentes;ì = média das observações; $\hat{O}_{\mathrm{i}}=$ efeito do nível de aveia no concentrado de ordem I, sendo $1=0 \%$ de aveia; $2=33 \%$ de aveia; $3=66 \%$ de aveia e $4=100 \%$ de aveia; é $\left(\hat{O}_{i}\right)=$ erro "a", corresponde à variação de lote dentro de tratamento; $\tilde{n}_{j}=$ efeito do subperíodo de alimentação de ordem $\mathrm{j}$, sendo $1=$ silagem de sorgo e $2=$ silagem de milho; (ôñ) $)_{\mathrm{ij}}=$ efeito da interação entre nível de aveia no concentrado e subperíodo de alimentação; $\breve{a}_{i \mathrm{ik}}=$ erro residual, assumindo distribuição normal com média igual a zero e variância ó ${ }^{2}$.

\section{Resultados e Discussão}

Na Tabela 3, são apresentados os dados médios da composição bromatológica dos diferentes ingredientes utilizados na formulação das dietas fornecidas aos novilhos na fase de terminação em confinamento. Observa-se que o grão de aveia preta apresentou maior teor de proteína bruta e FDN que o grão de sorgo, menor digestibilidade e menor teor de energia digestível. Entre as silagens, observa-se que a silagem de milho apresentou maiores teores de matéria seca e proteína bruta, maiores digestibilidade e teor de energia digestível e menor porcentagem de FDN que a silagem de sorgo. Os valores obtidos por intemédio de análise bromatológica estão de acordo com os apresentados pelo NRC (1984), com exceção do teor de energia digestível, que foi inferior em todos os alimentos, porém estão de acordo com os resultados obtidos por Costa (2000) e Silva (1999).

Os dados médios para peso ao início do período de adaptação, ao início e ao final do período experimental, são apresentados na Tabela 4. Verifica-se que o peso ao início do período experimental foi influenciado pelo efeito do tratamento durante a adaptação. Observa-se

Tabela 3 - Composição média em termos de matéria seca total (MS), matéria orgânica total (MO), proteína bruta (PB), extrato etéreo (EE), fibra em detergente neutro (FDN), digestibilidade in vitro da matéria seca (DIVMS) e da matéria orgânica (DIVMO) e energia digestível (ED) dos ingredientes utilizados na formulação das dietas

Table 3 - Average composition in terms of total dry matter (DM), organic matter (OM), crude protein (CP), ether extract (EE), neutral detergent fiber (NDF), in vitro dry matter digestibility (IVDMD), in vitro organic matter digestibility (IVOMD) and digestible energy (DE) of ingredients used in the diets

\begin{tabular}{|c|c|c|c|c|c|c|c|c|}
\hline $\begin{array}{l}\text { Ingredientes } \\
\text { Ingredients }\end{array}$ & $\begin{array}{l}\text { MS (\%) } \\
\text { DM }\end{array}$ & $\begin{array}{c}\text { MO (\%) } \\
O M\end{array}$ & $\begin{array}{c}\mathrm{PB}(\%) \\
\quad C P\end{array}$ & $\begin{array}{c}\mathrm{EE}(\%) \\
E E\end{array}$ & $\begin{array}{c}\text { FDN }(\%) \\
N D F\end{array}$ & $\begin{array}{c}\text { DIVMS }(\%) \\
I V D M D\end{array}$ & $\begin{array}{l}\text { DIVMO }(\%) \\
\text { IVOMD }\end{array}$ & $\begin{array}{c}\mathrm{ED}(\mathrm{Mcal} / \mathrm{kg}) \\
E D\end{array}$ \\
\hline $\begin{array}{l}\text { Grão de sorgo } \\
\text { Sorghum grain }\end{array}$ & 84,74 & 83,61 & 6,88 & 2,02 & 16,10 & 79,82 & 80,95 & 3,590 \\
\hline $\begin{array}{l}\text { Grão de aveia } \\
\text { Oat grain }\end{array}$ & 87,10 & 84,58 & 13,68 & 4,24 & 29,30 & 68,13 & 71,42 & 3,179 \\
\hline $\begin{array}{l}\text { Silagem de sorgo } \\
\text { Sorghum silage }\end{array}$ & 29,48 & 27,97 & 5,50 & 2,18 & 58,16 & 52,62 & 52,89 & 2,296 \\
\hline $\begin{array}{l}\text { Silagem de milho } \\
\text { Corn silage }\end{array}$ & 36,60 & 35,19 & 8,04 & 3,09 & 54,36 & 58,47 & 58,24 & 2,563 \\
\hline
\end{tabular}


que, durante os sete dias de adaptação, os animais alimentados com maior porcentagem de sorgo no concentrado ( $0 \%$ aveia e $33 \%$ aveia) perderam, em média, $0,482 \mathrm{~kg}$ de peso por dia, enquanto os que receberam dietas com maior porcentagem de aveia (66\% aveia e $100 \%$ aveia) ganharam $0,756 \mathrm{~kg} /$ dia.

O período de adaptação visa amenizar as mudanças que ocorrem no meio ruminal com a transição de uma dieta à base de forragem para uma dieta mais concentrada. $\mathrm{O}$ desenvolvimento de uma microflora estável com a nova condição não é imediato, pois, de acordo com Macallister \& Cheng (1996), com a introdução de grão de cereal na dieta, aumenta o número de bactérias produtoras de ácido lático e, simultaneamente, o número de bactérias que metabolizam este ácido, diminuindo o acúmulo de ácido lático no rúmen, sendo que, com o tempo, o número de bactérias produtoras de ácido lático diminui, retornando o ecossistema ruminal a uma condição estável. No entanto, se a transição for abrupta, podem ocorrer acúmulo de ácido lático no rúmen e dominância de bactérias ácido tolerantes, criando uma condição instável, o $\mathrm{pH}$ do rúmen decresce abaixo de 5 e o animal pode sofrer de acidose.

Os resultados obtidos refletem a necessidade de uma adaptação mais lenta para os animais alimentados com alta concentração de sorgo na dieta. A diferença no ganho de peso dos animais durante a adaptação deve estar relacionada à composição química dos alimentos utilizados, bem como à sua influência sobre a cinética ruminal. Segundo Johnson \& Boyles (1991), o grão de aveia é um grão ideal para ser utilizado em uma dieta no período inicial do confinamento de bovinos, devido ao alto conteúdo de casca e fibra, facilitando a adaptação dos animais ao consumo de grãos e, após, substituindo gradualmente a aveia por outro grão de maior densidade energética.

Os valores médios referentes ao consumo de matéria seca são apresentados na Tabela 5 e estão dispostos de acordo com o nível de substituição do grão de sorgo pelo grão de aveia preta no concentrado e o subperíodo de alimentação. O consumo de matéria seca representa um dos fatores primários na conversão da forragem em produto animal (Waldo, 1986), sendo que o consumo de matéria seca digestível é mais afetado pelo consumo de matéria seca que pela sua digestibilidade. Segundo Mertens (1992), o consumo de matéria seca é uma função do animal, por intermédio das variantes peso vivo, nível de produção, estado fisiológico, tamanho, entre outros; das caracte-

rísticas do alimento oferecido, como fibra, volume, capacidade de enchimento, densidade energética, necessidade de mastigação, entre outros; e das condições de alimentação, como a disponibilidade de alimento, taxa de lotação, espaço no cocho, tempo de acesso ao alimento, freqüência de alimentação etc, bem como da interação entre estes fatores. Como no presente experimento, as variantes relacionadas aos animais e as condições de alimentação foram semelhantes para todos os tratamentos, o consumo de matéria seca será discutido em função das características dos alimentos que compunham as dietas.

Analisando os dados de consumo de matéria seca, verificou-se efeito significativo de tratamento e tipo de silagem, bem como da interação destes dois fatores. Observa-se que não houve efeito do nível de aveia no concentrado sobre o consumo de matéria seca, expresso nas diferentes formas, no primeiro subperíodo de confinamento, em que os animais receberam como fonte de volumoso a silagem de sorgo forrageiro. No entanto, no segundo subperíodo de confinamento, quando a fonte de volumoso foi a silagem de milho, houve redução linear no CMS, expresso nas diferentes formas, com o aumento no nível de substituição do grão de sorgo pelo grão de aveia preta. Observou-se redução de $0,009797 \mathrm{~kg}$ no CMSD a cada ponto percentual de substituição do sorgo pela aveia na fração concentrado da dieta.

$\mathrm{O}$ efeito da interação entre o nível de aveia no concentrado e o tipo de silagem para consumo de matéria seca, considerando uma avaliação

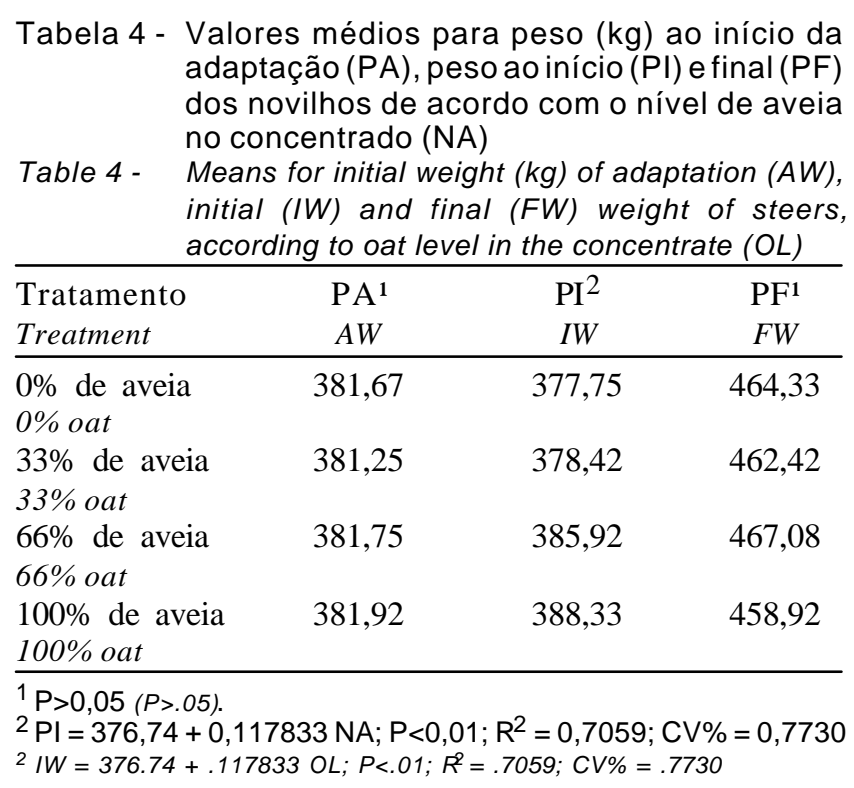

Tabela 4 - Valores médios para peso $(\mathrm{kg})$ ao início da adaptação (PA), peso ao início (PI) e final (PF) dos novilhos de acordo com o nível de aveia concentrado (NA) initial (IW) and final (FW) weight of steers, according to oat level in the concentrate $(O L)$ 
Tabela 5 - Valores médios para consumo de matéria seca (CMS) expresso por dia (CMSD), em relação ao peso vivo (CMSPV) e em relação ao peso metabólico (CMSTM) de acordo com o nível de aveia no concentrado (NA) e o tipo de silagem

Table 5 - Means for dry matter intake in kg/animal/day (DMID), in percentage of live weight (DMIP) and in relation to metabolic weight (DMIM) according to oat level in the concentrate $(O L)$ and silage type

\begin{tabular}{|c|c|c|c|}
\hline \multirow[t]{2}{*}{$\begin{array}{l}\text { Tratamento } \\
\text { Treatment }\end{array}$} & \multicolumn{2}{|c|}{$\begin{array}{l}\text { Silagem* } \\
\text { Silage* }\end{array}$} & \multirow[t]{2}{*}{$\begin{array}{l}\text { Média } \\
\text { Mean }\end{array}$} \\
\hline & $\begin{array}{l}\text { Sorgo } \\
\text { Sorghum }\end{array}$ & $\begin{array}{l}\text { Milho } \\
\text { Corn }\end{array}$ & \\
\hline & \multicolumn{3}{|c|}{$\begin{array}{l}\text { CMSD (kg/animal/dia) } \\
\text { DMID (kg/animal/day) }\end{array}$} \\
\hline $\begin{array}{l}0 \% \text { de aveia } \\
0 \% \text { oat }\end{array}$ & 9,017 & 11,233 & 10,125 \\
\hline $\begin{array}{l}33 \% \text { de aveia } \\
33 \% \text { oat }\end{array}$ & 9,140 & 10,690 & 9,915 \\
\hline $\begin{array}{l}66 \% \text { de aveia } \\
66 \% \text { oat }\end{array}$ & 9,172 & 10,521 & 9,847 \\
\hline $\begin{array}{l}100 \% \text { de aveia } \\
100 \% \text { oat } \\
\text { Média }\end{array}$ & 8,807 & 10,201 & 9,504 \\
\hline \multirow[t]{2}{*}{ Mean } & $9,034 \mathrm{~b}$ & $10,661 \mathrm{a}$ & \\
\hline & \multicolumn{3}{|c|}{$\begin{array}{c}\text { CMSPV }(\mathrm{kg} / 100 \mathrm{~kg} \text { de peso vivo }) \\
\text { DMIP }(\mathrm{kg} / 100 \mathrm{~kg} \text { of live weight })\end{array}$} \\
\hline $\begin{array}{l}0 \% \text { de aveia } \\
0 \% \text { oat }\end{array}$ & 2,252 & 2,532 & 2,392 \\
\hline $\begin{array}{l}33 \% \text { de aveia } \\
33 \% \text { oat }\end{array}$ & 2,277 & 2,411 & 2,344 \\
\hline $\begin{array}{l}66 \% \text { de aveia } \\
66 \% \text { oat }\end{array}$ & 2,263 & 2,360 & 2,311 \\
\hline $\begin{array}{l}100 \% \text { de aveia } \\
100 \% \text { oat }\end{array}$ & 2,160 & 2,302 & 2,231 \\
\hline \multirow{2}{*}{$\begin{array}{l}\text { Média } \\
\text { Mean }\end{array}$} & $2,238 b$ & $2,401 \mathrm{a}$ & \\
\hline & \multicolumn{3}{|c|}{$\begin{array}{l}\text { CMSTM (g/unidade de peso metabólico) } \\
\text { DMIM (g/unit of metabolic weight) }\end{array}$} \\
\hline $\begin{array}{l}0 \% \text { de aveia } \\
0 \% \text { oat }\end{array}$ & 100,74 & 116,22 & 108,48 \\
\hline $\begin{array}{l}33 \% \text { de aveia } \\
33 \% \text { oat }\end{array}$ & 101,92 & 110,65 & 106,28 \\
\hline $\begin{array}{l}66 \% \text { de aveia } \\
66 \% \text { oat }\end{array}$ & 101,56 & 108,44 & 105,00 \\
\hline $\begin{array}{l}100 \% \text { de aveia } \\
100 \% \text { oat }\end{array}$ & 97,05 & 105,63 & 101,34 \\
\hline $\begin{array}{l}\text { Média } \\
\text { Mean }\end{array}$ & $100,32 b$ & $110,23 a$ & \\
\hline
\end{tabular}

$a, b$, na mesma linha diferem $(P<0,01)$ pelo teste ' $t$ ' na comparação entre silagens.

${ }^{*}$ CMSD, CMSPV, CMSTM, para a silagem de sorgo: $P>0,05$. CMSD para a silagem de milho: $Y=11,14881-0,009797$ NA; $\mathrm{P}<0,01 ; \mathrm{R}^{2}=0,5797 ; \mathrm{CV} \%=3,04$

CMSPV para a silagem de milho: $Y=2,512183-0,002226 \mathrm{NA}$; $\mathrm{P}<0,01 ; \mathrm{R}^{2}=0,6262 ; \mathrm{CV} \%=2,78$.

CMSTM para a silagem de milho: $Y=115,303558-0,101950$ NA; $\mathrm{P}<0,01 ; \mathrm{R}^{2}=0,6187 ; \mathrm{CV} \%=2,82$.

$a, b$ : within a line, differ $(P<.01)$ by " $t$ " test for the comparison between silages. ${ }^{*} D M I D, D M I P, D M I M$, for sorghum silage: $P>05$

DMID for corn silage: $Y=11.14881-.009797 \mathrm{OL} ; P<.01 ; R^{2}=.5797 ; \mathrm{CV} \%=3.04$. DMIP for corn silage: $Y=2.512183-.002226 \mathrm{OL} ; P<.01 ; R^{2}=.6262 ; C V \%=2.78$. DMIM for corn silage: $Y=115.303558-.101950$ OL; $P<.01 ; R^{2}=.6187$; $C V \%=2.82$

R. Bras. Zootec., v.32, n.2, p.437-448, 2003 simplificada, está de acordo com o conceito mais aceito para a regulação do consumo em ruminantes. Este conceito envolve as características da dieta, em que o controle do consumo de dietas mais digestíveis e densas energeticamente é primeiramente realizado pelo controle metabólico ou é geralmente limitado pela necessidade nutricional do animal. Já o consumo de dietas menos densas energeticamente ou menos digestíveis é primeiramente controlado fisicamente ou é limitado pelo espaço ocupado dentro do trato gastrointestinal (Waldo, 1986).

O consumo de matéria seca, quando o volumoso foi a silagem de sorgo, pode ter sido regulado pela ação destes dois fatores, ou seja, nas dietas com maior proporção de grão de sorgo no concentrado e maior concentração energética, em função da maior digestibilidade da matéria orgânica (Tabela 3), o controle do consumo foi metabólico, considerando-se que o animal atingiu o requerimento de energia para o seu nível de produção. No entanto, nos tratamentos com maior proporção de grão de aveia no concentrado e menor densidade de energia digestível, o consumo foi regulado fisicamente por meio do consumo de FDN, que, de acordo com Waldo (1986), é o melhor e mais simples fator para predizer o consumo voluntário de matéria seca por ruminantes, concordando com o estudo de Mertens (1992), o qual sugere que a FDN mede melhor a propriedade dos alimentos em ocupar espaço que os componentes fibra bruta e fibra em detergente ácido (FDA). Estas hipóteses podem ser concretizadas quando se avaliam o consumo de FDN, apresentado na Tabela 6, e o consumo de energia digestível, apresentado na Tabela 7 . Verifica-se que o consumo de energia digestível diário, quando se utilizou a silagem de sorgo forrageiro, foi reduzido com o aumento da proporção de aveia na dieta a uma magnitude de 0,016449 Mcal para cada ponto percentual de aveia em substituição ao sorgo. Já com o mesmo volumoso, o consumo diário de FDN aumentou linearmente com o nível de aveia na dieta, em nível de $0,004167 \mathrm{~kg}$ de FDN para cada ponto percentual de aveia em substituição ao sorgo.

Analisando-se estes dados, pode-se deduzir que os animais alimentados com silagem de sorgo associados com concentrado à base de grão de aveia não conseguiram elevar o consumo de matéria seca para atender suas necessidades energéticas, em função da limitação física pelo elevado consumo de FDN. Já com concentrados à base de sorgo, o consumo de matéria seca não foi elevado até o máximo consumo 
de FDN, em função da limitação energética, devido ao maior consumo de energia digestível. Conrad (1964), citado por Allen (1996), sugere que existe um ponto de digestibilidade no qual a limitação no consumo de matéria seca pela distensão física do trato gastrointestinal é substituída pela limitação da satisfação da demanda energética. No entanto, este ponto de transição não é fixo, devendo ocorrer na interseção da curva de distensão com a curva de requerimento

Tabela 6 - Valores médios para consumo de fibra em detergente neutro por dia (CFDND) e em relação ao peso vivo (CFDNPV), de acordo com o nível de aveia no concentrado (NA) e o tipo de silagem

Table 6 - Means for consumption of neutral detergent fiber per day (NDFID) and in relation to live weight (NDFIP), according to oat level in the concentrate $(O L)$ and silage type

\begin{tabular}{|c|c|c|c|}
\hline \multirow[t]{2}{*}{$\begin{array}{l}\text { Tratamento } \\
\text { Treatment }\end{array}$} & \multicolumn{2}{|c|}{$\begin{array}{l}\text { Silagem* } \\
\text { Silage* }\end{array}$} & \multirow[t]{2}{*}{$\begin{array}{l}\text { Média } \\
\text { Mean }\end{array}$} \\
\hline & $\begin{array}{l}\text { Sorgo } \\
\text { Sorghum }\end{array}$ & $\begin{array}{l}\text { Milho } \\
\text { Corn }\end{array}$ & \\
\hline & \multicolumn{3}{|c|}{$\begin{array}{l}\text { CFDND (kg/animal/dia) } \\
\text { NDFID (kg/animal/day) }\end{array}$} \\
\hline $\begin{array}{l}0 \% \text { de aveia } \\
0 \% \text { oat }\end{array}$ & 3,642 & 4,474 & 4,058 \\
\hline $\begin{array}{l}33 \% \text { de aveia } \\
33 \% \text { oat }\end{array}$ & 3,858 & 4,434 & 4,146 \\
\hline $\begin{array}{l}66 \% \text { de aveia } \\
66 \% \text { oat }\end{array}$ & 4,041 & 4,540 & 4,290 \\
\hline $\begin{array}{l}100 \% \text { de aveia } \\
100 \% \text { oat }\end{array}$ & 4,045 & 4,576 & 4,312 \\
\hline \multirow{2}{*}{$\begin{array}{l}\text { Média } \\
\text { Mean }\end{array}$} & $3,896 \mathrm{~b}$ & $4,506 a$ & \\
\hline & \multicolumn{3}{|c|}{$\begin{array}{l}\text { CFDNPV (kg/100 kg de peso vivo) } \\
\text { NDFIP (kg/100 kg of live weight) }\end{array}$} \\
\hline $\begin{array}{l}0 \% \text { de aveia } \\
0 \% \text { oat }\end{array}$ & 0,910 & 1,008 & 0,959 \\
\hline $\begin{array}{l}33 \% \text { de aveia } \\
33 \% \text { oat }\end{array}$ & 0,961 & 1,000 & 0,981 \\
\hline $\begin{array}{l}66 \% \text { de aveia } \\
66 \% \text { oat }\end{array}$ & 0,997 & 1,018 & 1,008 \\
\hline $\begin{array}{l}100 \% \text { de aveia } \\
100 \% \text { oat }\end{array}$ & 0,992 & 1,033 & 1,012 \\
\hline $\begin{array}{l}\text { Média } \\
\text { Mean }\end{array}$ & $0,965 \mathrm{~b}$ & $1,015 \mathrm{a}$ & \\
\hline
\end{tabular}

$a$, $b$ : na mesma linha diferem $(P<0,01)$ pelo teste ' $t$ ' na comparação entre silagens.

${ }^{\star}$ CFDND para a silagem de sorgo: $Y=3,689149+0,004167 \mathrm{NA}$; $\mathrm{P}<0,01 ; \mathrm{R}^{2}=0,4386 ; \mathrm{CV} \%=4,70$.

CFDNPV para a silagem de sorgo: $Y=0,922941-0,000845$ NA; $\mathrm{P}<0,01 ; \mathrm{R}^{2}=0,3635 ; \mathrm{CV} \%=4,51$.

CFDND, CFDNPV para a silagem de milho: $P>0,05$.

$a, b$ : within line, differ $(P<.01)$ by " $t$ " test for the comparison between silages. NDFID for sorghum silage: $Y=3.689149+0.004167 O L ; P<.01 ; R^{2}=.4386$;

$C V \%=4.70$.

NDFIP for sorghum silage: $Y=.922941-.000845$ OL; $P<.01 ; R^{2}=.3635$;

$C V \%=4.51$.

NDFID, NDFIP for corn silage: $P>05$. nutricional (Waldo, 1986).

Entretanto, quando foi utilizada a silagem de milho, em que o consumo de matéria seca decresceu linearmente com a inclusão de aveia em substituição ao sorgo, o fator supressor do consumo foi a distensão do trato gastrointestinal, que, conforme Allen (1996), resulta do restrito fluxo da digesta através do trato gastrointestinal, sendo uma importante limitação no consumo de matéria seca, particularmente quando a qualidade da dieta decresce. Pode-se observar que o consumo de FDN no segundo subperíodo de confinamento, quando foi utilizada a silagem de milho, não diferiu estatisticamente entre os tratamentos (Tabela 6). Infere-se, portanto, que os animais consumiram matéria seca visando atingir seus requerimentos energéticos até o limite máximo de ingestão de FDN, que apresentou valor médio de 4,506 kg de FDN/animal/dia ou então 1,015\% do peso vivo, expressão mais adequada, visto que a capacidade do retículo-rúmen é determinada como uma função linear do peso vivo (Allen, 1996).

Os resultados encontrados para consumo de FDN, em porcentagem do peso vivo, concordam com os resultados encontrados por Eifert (2000), que observou consumo médio de FDN de $0,991 \%$ do peso vivo para bezerros alimentados com silagem de sorgo e diferentes níveis de concentrado.

Em uma avaliação mais complexa, o consumo de matéria seca considera a taxa de passagem do alimento pelo trato gastrointestinal, que, conforme revisão realizada por Allen (1996), o tempo de retenção das partículas no retículo-rúmen está negativamente relacionado com a densidade das partículas, em que partículas menos densas têm menor taxa de passagem do retículo-rúmen, pois estas partículas estão em suspensão longe do orifício retículo-omasal, quando ocorrem as contrações do retículo, permitindo a passagem das partículas para o omaso. Considerando que o grão de sorgo possui maior densidade (peso/ volume) que o grão de aveia preta, estas considerações podem ajudar a explicar o maior consumo de matéria seca por parte dos animais alimentados com concentrado à base de sorgo.

Ainda analisando os dados de consumo de matéria seca apresentados na Tabela 5, observa-se que o consumo expresso em $\mathrm{kg}$ de matéria seca/animal/dia aumentou do primeiro para o segundo subperíodo alimentar, o que está relacionado em maior proporção ao aumento no peso vivo dos animais, já que a capacidade física do retículo-rúmen é uma função 
Tabela 7 - Valores médios para consumo de energia digestível por dia (CEDD), em relação ao peso vivo (CEDPV), em relação ao peso metabólico (CEDTM), de acordo com o nível de aveia no concentrado (NA) e o tipo de silagem

Table 7 - Means for digestible energy intake (DEID), in relation to live weight (DEIP), in relation to metabolic weight (DEIM), according to oat level in the concentrate (NA) and silage type

\begin{tabular}{|c|c|c|c|}
\hline \multirow[t]{2}{*}{$\begin{array}{l}\text { Tratamento } \\
\text { Treatment }\end{array}$} & \multicolumn{2}{|c|}{$\begin{array}{l}\text { Silagem* } \\
\text { Silage* }\end{array}$} & \multirow[t]{2}{*}{$\begin{array}{l}\text { Média } \\
\text { Mean }\end{array}$} \\
\hline & $\begin{array}{l}\text { Sorgo } \\
\text { Sorghum }\end{array}$ & $\begin{array}{l}\text { Milho } \\
\text { Corn }\end{array}$ & \\
\hline & \multicolumn{3}{|c|}{$\begin{array}{c}\text { CEDD (MCal/animal/dia) } \\
\text { DEID (MCal/animal/day) }\end{array}$} \\
\hline $\begin{array}{l}0 \% \text { de aveia } \\
0 \% \text { oat }\end{array}$ & 24,922 & 32,540 & 28,731 \\
\hline $\begin{array}{l}33 \% \text { de aveia } \\
33 \% \text { oat }\end{array}$ & 24,877 & 30,558 & 27,718 \\
\hline $\begin{array}{l}66 \% \text { de aveia } \\
66 \% \text { oat }\end{array}$ & 24,571 & 29,661 & 27,116 \\
\hline $\begin{array}{l}100 \% \text { de aveia } \\
100 \% \text { oat }\end{array}$ & 23,206 & 28,351 & 25,778 \\
\hline \multirow{2}{*}{$\begin{array}{l}\text { Média } \\
\text { Mean }\end{array}$} & $24,394 b$ & $30,278 \mathrm{a}$ & \\
\hline & \multicolumn{3}{|c|}{$\begin{array}{l}\text { CEDPV (Mcal/100 kg de peso vivo) } \\
\text { DEIP (Mcal/100 kg of live weight) }\end{array}$} \\
\hline $\begin{array}{l}0 \% \text { de aveia } \\
0 \% \text { oat }\end{array}$ & 6,225 & 7,336 & 6,780 \\
\hline $\begin{array}{l}33 \% \text { de aveia } \\
33 \% \text { oat }\end{array}$ & 6,197 & 6,893 & 6,545 \\
\hline $\begin{array}{l}66 \% \text { de aveia } \\
66 \% \text { oat }\end{array}$ & 6,063 & 6,653 & 6,358 \\
\hline $\begin{array}{l}100 \% \text { de aveia } \\
100 \% \text { oat }\end{array}$ & 5,690 & 6,398 & 6,044 \\
\hline $\begin{array}{l}\text { Média } \\
\text { Mean }\end{array}$ & $6,044 b$ & $6,820 \mathrm{a}$ & \\
\hline
\end{tabular}

CEDTM (Cal/unidade de peso metabólico) CEDTM (Cal/unit metabolic weight)

\begin{tabular}{llll} 
0\% de aveia & 278,46 & 336,66 & 307,56 \\
\cline { 2 - 3 } $\begin{array}{l}\text { \% oat } \\
33 \% \text { de aveia }\end{array}$ & 277,41 & 316,30 & 296,85 \\
$\begin{array}{l}33 \% \text { oat } \\
66 \% \text { de aveia }\end{array}$ & 272,05 & 305,70 & 288,88 \\
$\begin{array}{l}\text { 66\% oat } \\
\begin{array}{l}100 \% \text { de aveia } \\
100 \% \text { oat }\end{array}\end{array}$ & 255,71 & 293,56 & 274,64 \\
$\begin{array}{l}\text { Média } \\
\text { Mean }\end{array}$ & $270,91 \mathrm{~b}$ & $313,05 \mathrm{a}$ & \\
\hline
\end{tabular}

$a, b$, na mesma linha diferem $(P<0,01)$ pelo teste 't' na comparação entre silagens.

a,b: within line, differ $(P<.01)$ by " $t$ " test for the comparison between silages. * CEDD para a silagem de sorgo (DEID for sorghum silage): $\mathrm{Y}=25,212368-0,016449 \mathrm{NA} ; \mathrm{P}<0,02 ; \mathrm{R}^{2}=0,2328 ; \mathrm{CV} \%=4,76$. CEDD para a silagem de milho(DEID for corn silage): $Y=32,288316$ $-0,040411 \mathrm{NA} ; \mathrm{P}<0,01 ; \mathrm{R}^{2}=0,7452 ; \mathrm{CV} \%=3,04$.

CEDPV para a silagem de sorgo(DEIP for corn silage): $Y=6,304828$ $-0,005239 \mathrm{NA} ; \mathrm{P}<0,01 ; R^{2}=0,3545 ; \mathrm{CV} \%=4,55$.

CEDPV para a silagem de milho(DEIP for corn silage): $Y=7,275722$ - 0,00916 NA; $P<0,01 ; R^{2}=0,7785 ; C V \%=2,79$.

CEDTM para a silagem de sorgo (DEIM for sorghum silage): $Y=281,941776-0,221781 \mathrm{NA} ; \mathrm{P}<0,01 ; R^{2}=0,3240 ; C V \%=4,60$. CEDTM para a silagem de milho (DEIM for corn silage): $Y=333,937758$ - 0,419795 NA; $P<0,01 ; R^{2}=0,7734 ; C V \%=2,82$. linear do peso vivo (Allen, 1996). Entretanto, também ocorreu acréscimo do primeiro para o segundo subperíodo alimentar, quando o consumo de matéria seca foi expresso em porcentagem do peso vivo, o mesmo comportamento foi observado quando o consumo foi expresso em g/unidade de peso metabólico.

A variação no consumo em relação ao peso vivo e ao peso metabólico está em função, principalmente, da qualidade do volumoso utilizado nos dois subperíodos. No segundo subperíodo, foi utilizada a silagem de milho com menor concentração de FDN e maior digestibilidade e maior concentração de energia digestível que a silagem de sorgo, utilizado no primeiro subperíodo. A menor concentração de FDN da silagem de milho permitiu maior consumo de matéria seca, considerando-se o efeito do fator distensão do trato gastrointestinal, pois, analisando o consumo de FDN apresentado na Tabela 6, verifica-se que os valores médios em relação ao peso vivo foram similares entre as silagens de sorgo e de milho, apesar da diferença estatística $(\mathrm{P}<0,01)$, com valores de 0,965 e $1,015 \%$, respectivamente.

A silagem de milho também apresentou maior concentração de matéria seca, característica dos híbridos utilizados para a confecção das silagens, reduzindo o efeito potencial que a porcentagem de água na dieta tem sobre a redução do consumo, quando silagens são utilizadas (Waldo, 1986). Chase (1979), citado por Waldo (1986), concluiu que o consumo de matéria seca, em estudos com silagens, foi reduzido cerca de $0,02 \mathrm{~kg} / 100 \mathrm{~kg}$ de peso vivo para cada unidade percentual de incremento no conteúdo de água na dieta.

O maior consumo de matéria seca, conciliado à maior concentração energética proporcionada pela silagem de milho, refletiu diretamente no consumo de energia digestível, que foi superior mesmo quando expressa em porcentagem do peso vivo e em relação ao peso metabólico (Tabela 7). As características bromatológicas das plantas utilizadas para a confecção da silagem são mais importantes que as espécies utilizadas. Silva et al. (2000) não verificaram diferenças estatísticas no consumo de matéria seca, proteína bruta, nutrientes digestíveis totais e FDN entre as silagens de milho e sorgo, quando estas apresentaram concentrações semelhantes destes nutrientes. O maior aporte de energia consumido no segundo período possibilitou a manutenção do ganho de peso diário durante todo o período de confinamento (Tabela 8). 
A estabilidade do ganho de peso durante o período de confinamento representa um ponto muito importante no planejamento do sistema de confinamento, pois permite estimar a data de comercialização dos animais, visando realizar a venda no período de maior vantagem econômica, que, historicamente no Rio Grande do Sul, se situa no mês de agosto e setembro (ANUALPEC, 2000), período em que se reduz a oferta de animais terminados em pastagem nativa e praticamente não existe oferta de animais terminados em pastagem cultivada de inverno. O planejamento forrageiro é uma grande ferramenta nas mãos do produtor rural, que pode lançar mão da utilização de volumosos qualitativamente superiores no período final do confinamento, em detrimento do aumento do nível de concentrado na dieta, visando suprir o requerimento energético do animal, que aumenta em função das mudanças que ocorrem, principalmente, na composição do ganho de peso com a evolução do peso vivo, onde animais mais pesados depositam, proporcionalmente, mais gordura por quilo de ganho de peso, necessitando de maior teor de energia na dieta (NRC, 1996). Observa-se, na Tabela 9, que para depositar $1 \mathrm{~kg}$ de ganho de peso foram necessários $23,4 \%$ mais energia digestível no segundo que no primeiro subperíodo alimentar (25,529 vs $20,686 \mathrm{Mcal} / \mathrm{kg}$ de ganho de peso). $\mathrm{O}$ maior requerimento energético refletiu diretamente sobre a conversão alimentar (Tabela 9), porém em menor magnitude, em função da maior concentração energética da silagem de milho frente à de sorgo. No segundo subperíodo alimentar, foram necessários $17,4 \%$ mais matéria seca para depositar um quilo de ganho de peso que no primeiro (9,001 vs $7,670 \mathrm{~kg} / \mathrm{kg}$ de ganho).

O ganho de peso, que é apresentado na Tabela 8, também foi influenciado pelo nível de substituição do sorgo pelo grão de aveia, porém não houve interação $(\mathrm{P}>0,05)$ entre este e o tipo de silagem. Observa-se que, em média, o ganho de peso decresceu linearmente com o aumento do nível de aveia na fração concentrado da dieta, ao grau de $-0,002285 \mathrm{~kg}$ para cada ponto percentual de substituição.

Stock et al. (1990) cita que, em confinamentos comerciais, tem sido dada ênfase ao máximo consumo de energia acima da mantença para produzir ganhos mais eficientes e, segundo o NRC (1984), a eficiência de utilização dos nutrientes da dieta para ganho de peso depende da concentração energética da dieta. Isso explica o comportamento do GMD, uma vez que o consumo de energia digestível decresceu
Tabela 8 - Valores médios para ganho de peso médio diário (GMD, kg/animal) de acordo com o nível de aveia no concentrado (NA) e o tipo de silagem

Table 8 - Means for daily weight gain (DWG, kg/animal) according to oat level in the concentrate $(O L)$ and silage type

\begin{tabular}{lccc}
\hline $\begin{array}{l}\text { Tratamento } \\
\text { Treatment }\end{array}$ & \multicolumn{2}{c}{$\begin{array}{c}\text { Silagem* } \\
\text { Silage* }\end{array}$} & $\begin{array}{c}\text { Média } \\
\text { Mean }\end{array}$ \\
\cline { 2 - 3 } & $\begin{array}{c}\text { Sorgo } \\
\text { Sorghum }\end{array}$ & $\begin{array}{c}\text { Milho } \\
\text { Corn }\end{array}$ & \\
\hline $\begin{array}{l}\text { 0\% de aveia } \\
\text { 0\% oat }\end{array}$ & 1,290 & 1,294 & 1,292 \\
$\begin{array}{l}\text { 33\% de aveia } \\
\text { 33\% oat }\end{array}$ & 1,307 & 1,195 & 1,251 \\
$\begin{array}{l}\text { 66\% de aveia } \\
33 \% \text { oat }\end{array}$ & 1,102 & 1,331 & 1,217 \\
$\begin{array}{l}\text { 100\% de aveia } \\
\text { 100\% oat }\end{array}$ & 1,112 & 0,990 & 1,051 \\
$\begin{array}{l}\text { Média } \\
\text { Mean }\end{array}$ & $1,203 \mathrm{a}$ & $1,202 \mathrm{a}$ & \\
\hline
\end{tabular}

$a, b$, na mesma linha diferem $(P<0,05)$ pelo teste 't' na comparação entre silagens.

$a, b$ : within line, differ $(P<.05)$ by "t" test for the comparison between silages. ${ }^{*} \mathrm{GMD}=1,316399-0,002285 \mathrm{NA} ; \mathrm{P}<0,01 ; \mathrm{R}^{2}=0,4576 ; \mathrm{CV}(\%)=8,04$. ${ }^{*} D W G=1.316399-.002285 \mathrm{OL} ; P<.01 ; R^{2}=.4576 ; \mathrm{CV}(\%)=8.04$.

linearmente com o aumento do nível de aveia na dieta, com ambos os volumosos (Tabela 7), e a conversão de energia digestível em ganho de peso (Tabela 9) não diferiu $(\mathrm{P}>0,05)$ entre os diferentes níveis de substituição, sendo que na média foram necessários 23,107 Mcal/kg de ganho de peso, relacionando diretamente o maior GMD ao maior consumo de energia digestível.

Observa-se que o GMD para as dietas com maior proporção de grão de sorgo no concentrado foi superior ao ganho de $1,2 \mathrm{~kg} / \mathrm{animal} / \mathrm{dia}$ esperados. Analisando os valores médios do ganho de peso, observa-se que o grão de aveia preta pode substituir o grão de sorgo em até $66 \%$, sem prejuízo para o ganho de peso esperado. No entanto, para a dieta com $100 \%$ de grão de aveia, o ganho ficou abaixo do esperado, com média de $1,051 \mathrm{~kg}$. Analisando resultados encontrados na literatura, conclui-se que o grão de aveia, quando utilizado como alimento concentrado na dieta de novilhos, tem bom potencial para a produção de ganhos de peso ao redor de $1 \mathrm{~kg} / \mathrm{dia}$, excelentes para animais em fase de recria, durante a qual a exigência energética é mais baixa. Alves Filho et al. (2001) verificaram GMD de 1,063 e 1,262 kg, quando novilhos foram suplementados em pastagem cultivada de 
azevém mais aveia com $1 \%$ do peso vivo na forma de grão de aveia preta ou grão de sorgo, respectivamente. Goi et al. (1998), utilizando aveia branca, observaram GMD de 1,069 kg para novilhos Hereford alimentados com relação volumoso:concentrado de 50:50. Corah et al. (1973) observaram que o aumento no nível de grão de aveia na dieta aumentou o GMD, variando de 0,8 a $1,1 \mathrm{~kg}$ para os animais que recebe$\operatorname{ram} 2,7$ e 5,4 $\mathrm{kg}$ de aveia, respectivamente. $\mathrm{O}$ incremento no GMD observado foi mais relacionado ao aumento no nível de concentrado na dieta, concordando com os resultados observados por Owens et al. (1997), que relataram ganhos de $1,5 \mathrm{~kg}$ utilizando o grão de aveia como concentrado, porém trabalharam com uma relação volumoso:concentrado média de 15:85, elevando muito o nível de energia da dieta em relação ao presente experimento.

Os dados médios para conversão alimentar são apresentados na Tabela 9, de acordo com o tratamento e o tipo de silagem. Não foi observada interação $(\mathrm{P}>0,05)$, por intermédio da análise de variância, entre nível de aveia no concentrado e tipo de silagem. Observa-se que a conversão alimentar piorou à medida que se elevou a proporção de grão de aveia na dieta, sendo a equação de regressão linear que melhor explica os resultados ( $\mathrm{Y}=7,703613+0,011421$ NA), onde para cada ponto percentual a mais de aveia no concentrado em substituição ao sorgo foi necessário mais $0,011421 \mathrm{~kg}$ de matéria seca para depositar um quilo de ganho de peso.

Os resultados observados para a conversão alimentar estão associados à qualidade das dietas e às necessidades dos animais, já que a conversão alimentar representa a relação entre quantidade de matéria seca consumida e ganho de peso. Constata-se que dietas com maior concentração de energia são mais eficientes na variável ganho de peso, para um mesmo estádio de desenvolvimento, melhorando a conversão alimentar. Estes resultados estão de acordo com os encontrados por Brondani et al. (2001), os quais observaram que animais alimentados com um nível mais alto de energia (32 vs $12 \%$ de concentrado na dieta) apresentaram maior GMD e, conseqüentemente, foram mais eficientes na conversão alimentar. Restle et al. (2000) citam que a eficiência biológica com que o animal transforma o alimento em ganho de peso depende, além da dieta alimentar (densidade energética, forma física, fermentação ruminal, água, etc), da categoria animal (idade, estado sexual, composição do ganho, raça), dos fatores ambientais (tem-
Tabela 9 - Valores médios para conversão alimentar (CA) e conversão de energia digestível (CED), de acordo com o nível de aveia no concentrado (NA) e o tipo de silagem

Table 9 - Means for fed conversion (FC) and digestible energy conversion (DEC), according to the oat level in the concentrate $(O L)$ and silage type

\begin{tabular}{lccc}
\hline Tratamento & \multicolumn{2}{c}{ Silagem* } & Média \\
Treatment & \multicolumn{2}{c}{ Silage* } & \\
\cline { 2 - 3 } & Sorgo & Milho & \\
& Sorghum & Corn & \\
\hline
\end{tabular}

CA (kg matéria seca consumida/kg peso vivo) FC ( $\mathrm{kg}$ dry matter consumed/kg of weight gain)

\begin{tabular}{|c|c|c|c|}
\hline $\begin{array}{l}0 \% \text { de aveia } \\
0 \% \text { oats }\end{array}$ & 7,139 & 8,683 & 7,911 \\
\hline $\begin{array}{l}33 \% \text { de aveia } \\
33 \% \text { oats }\end{array}$ & 6,990 & 9,009 & 8,000 \\
\hline $\begin{array}{l}66 \% \text { de aveia } \\
66 \% \text { oats }\end{array}$ & 8,536 & 7,903 & 8,220 \\
\hline $\begin{array}{l}100 \% \text { de aveia } \\
100 \% \text { oats }\end{array}$ & 8,015 & 10,409 & 9,212 \\
\hline $\begin{array}{l}\text { Média } \\
\text { Mean }\end{array}$ & $7,670 \mathrm{~b}$ & $9,001 \mathrm{a}$ & \\
\hline
\end{tabular}

CED (Mcal de energia digestível/kg de ganho de peso) DEC (Mcal of digestible energy/kg of weight gain)

\begin{tabular}{|c|c|c|c|}
\hline $\begin{array}{l}0 \% \text { de aveia } \\
0 \% \text { oats }\end{array}$ & 19,733 & 25,154 & 22,444 \\
\hline $\begin{array}{l}33 \% \text { de aveia } \\
33 \% \text { oats }\end{array}$ & 19,026 & 25,754 & 22,390 \\
\hline $\begin{array}{l}66 \% \text { de aveia } \\
66 \% \text { oats }\end{array}$ & 22,866 & 22,281 & 22,573 \\
\hline $\begin{array}{l}100 \% \text { de aveia } \\
100 \% \text { oats }\end{array}$ & 21,117 & 28,928 & 25,022 \\
\hline $\begin{array}{l}\text { Média } \\
\text { Mean }\end{array}$ & $20,686 b$ & $25,529 a$ & \\
\hline
\end{tabular}

a, b: na mesma linha diferem $(P<0,05)$ pelo teste 't' na comparação entre silagens.

$a, b$ : within line, differ $(P<.05)$ by "t" test for the comparison between silages. ${ }^{*} \mathrm{CA}=7,703613+0,011421 \mathrm{NA} ; \mathrm{P}<0,01 ; \mathrm{R}^{2}=0,2637 ; \mathrm{CV}(\%)=8,97$ ${ }^{*} F C=7.703613+0.011421 \mathrm{OL} ; P<.01 ; R^{2}=0.2637 ; \mathrm{CV}(\%)=8.97$ CED: $P>0,05$.

$D E C: P>05$.

peratura, umidade relativa do ar, entre outros) e do manejo dos animais (manejo da alimentação, espaço físico, bem-estar dos animais etc).

Ainda na Tabela 9, quando se avaliou a conversão alimentar por tipo de silagem, verificou-se que, apesar da maior concentração de energia digestível para as dietas com silagem de milho, ocorreu pior conversão alimentar, o que está relacionado à variação na composição do ganho de peso que ocorre quando varia o peso e o grau de acabamento do animal. Segundo o NRC (1996), quando se aumenta o peso do animal e quanto mais este se aproxima do peso a maturidade, maior é a proporção de gordura depositada 
em relação ao ganho de peso, necessitando, portanto, de maior aporte de energia para depositar $1 \mathrm{~kg}$ de ganho de peso. Esta afirmação ressalta os valores observados no presente trabalho, no qual se verifica que os novilhos alimentados durante a primeira fase do confinamento com a silagem de sorgo necessitaram de 7,670 Mcal de energia digestível para depositar $1 \mathrm{~kg}$ de ganho de peso, já na segunda fase, quando os animais foram alimentados com a silagem de milho, necessitaram de 9,001 Mcal de energia digestível, ou seja, $17,35 \%$ a mais de energia para depositar um $\mathrm{kg}$ de peso vivo.

\section{Conclusões}

A inclusão de grão de aveia preta em substituição ao grão de sorgo na dieta com relação volumoso:concentrado de $60: 40$ provocou limitação no consumo de matéria seca, no período de maior exigência energética do animal, e limitação no consumo de energia digestível, devido ao maior teor de FDN e à menor concentração de energia digestível do grão de aveia.

O ganho de peso médio diário diminuiu linearmente com o nível de substituição do grão de sorgo por aveia, no entanto, a substituição até o nível de $66 \%$ promoveu ganho de peso acima dos $1,2 \mathrm{~kg}$ esperados.

O aumento do nível de aveia preta na dieta reduziu a eficiência de transformação do alimento em ganho de peso, devido ao decréscimo causado na concentração energética da dieta.

Ambos os grãos são boas fontes de concentrado para a alimentação de novilhos, porém, para melhor eficiência no ganho de peso, recomenda-se não substituir o sorgo pelo grão de aveia a nível superior a $66 \%$.

A utilização de um volumoso de melhor qualidade (silagem de milho em relação a de sorgo), no período final do confinamento, proporcionando maior consumo de matéria seca e de energia digestível, permitiu a uniformidade do ganho de peso durante todo o período experimental.

\section{Literatura Citada}

ALLEN, M.S. Physical constraints on voluntary intake of forages by ruminants. Journal of Animal Science, v.74, p.3063-3075, 1996.

ALVES FILHO, D.C.; RESTLE, J.; ARBOITTE, M.Z. et al. Produção de machos superprecoce em condições de pastagem cultivada de inverno com suplementação de grão de aveia ou sorgo. In: REUNIÃO ANUAL DA SOCIEDADE BRASI-
LEIRA DEZOOTECNIA, 38., Piracicaba. Anais...Piracicaba: SBZ/Gmosis, [2001]. CD ROM. Nutrição de ruminantes. Nutr-750.

ANUALPEC. 2000. Anuário da pecuária brasileira. São Paulo: Oesp Gráfica SA. 359p.

ASSOCIATION OF OFFICIAL AGRICULTURAL CHEMISTS - AOAC. Official methods of the analysis. 11.ed. Washington, D.C.: 1970. 1015p.

AGRICULTURAL RESEARCH COUNCIL - ARC. The nutrients requeriments of ruminants livestock. Technical review by on Agricultural Research Council Working Patry, London: 1980. 351p.

BRONDANI, I.L.; SAMPAIO, A.A.M.; RESTLE, J. et al. Desempenho de tourinhos jovens de diferentes grupos genéticos confinados e alimentados com dois níveis de energia. In: REUNIÃO ANUAL DA SOCIEDADE BRASILEIRA DE ZOOTECNIA, 38., Piracicaba. Anais... Piracicaba: SBZ/Gmosis, [2001]. CD ROM. Nutrição de ruminantes. Nutr-723.

CORAH, L.R.; SAXTON, I.E.; BISHOP, A.H. et al. Fattening stters on hay and oats. Australian Journal of Experimental Agriculture and Animal Husbandry, v.13, p.487-494, 1973. COSTA, E.C.Desempenho em confinamento e características da carcaça e da carne de novilhos red angus superprecoce abatidos com diferentes pesos. Santa Maria: Universidade Federal de Santa Maria, 2001. 100p. Dissertação (Mestrado em Zootecnia) - Universidade Federal de Santa Maria, 2001.

EIFERT, E.C. Silagens de sorgo e de triticale associadas a níveis de concentrado para alimentação de terneiros de corte desmamados precocemente. Santa Maria: Universidade Federal de Santa Maria, 2000. 137p. Dissertação (Mestrado em Zootecnia) - Universidade Federal de Santa Maria, 2000.

FLOSS, E.L. O papel da aveia como componente de uma agricultura sustentável. In: REUNIÃO DA COMISSÃO BRASILEIRA DE PESQUISA DE AVEIA, 21., 2001 , Lages. Resultados experimentais... Lages: Universidade do Estado de Santa Catarina, 2001. p.11-22.

GOI, L.J.; SANCHEZ, L.M.B.; GONÇALVES, M.B.F. et al. Tratamentos físicos do grão de aveia branca (Avena sativa) na alimentação de bovinos. Ciência Rural, v.28, n.2, p.303-307, 1998.

JOHNSON, L.; BOYLES, S. Oats as a feed for beef cattle. Dakota: North Dakota State University Extension Service, 1991. 14p.

MACALLISTER, T.A.; CHENG, K.J. Microbial strategies in the ruminal digestion of cereal grains.Animal Feed Science Technology, v.62, p.29-36, 1996.

MARTINS, A.S.; ZEOULA, L.M.; PRADO, I.N. et al. Degradabilidade ruminal in situ da matéria seca e proteína bruta das silagens de milho e sorgo e de alguns alimentos concentrados. Revista Brasileira de Zootecnia v.28, n.5, p.1109-1117, 1999.

MERTENS, D.R. Análise da fibra e sua utilização na avaliação de alimentos e formulação de rações. In: SIMPÓSIO INTERNACIONAL DE RUMINANTES, REUNIÃO ANUAL DA SOCIEDADE BRASILEIRA DE ZOOTECNIA, 29, 1992, Lavras. Anais...Lavras: Sociedade Brasileira de Zootecnia, 1992. p.188-219.

NATIONAL RESEARCH COUNCIL - NRC. Nutrient requeriment of beef cattle. 6.ed. Washington, D.C.: 1984.50p.

NATIONAL RESEARCH COUNCIL - NRC. Nutrient requeriment of beef cattle. 7.ed., Washington, D.C.: 1996.232p. 
OWENS, F.N.; SECRIST, D.S.; HILL, W.J et al. The effect of grain source and grain processing on performance of feedlot cattle: a review. Journal of Animal Science, v.75, p.868879, 1997.

POORE, M.H.; MOORE, J.A.; SWINGLE, R.S. Differential passage rates and digestion of neutral detergent fiber from grain and forages in 30,60 and 90\% concentrate diets fed to steers. Journal of Animal Science, v.68, p.2965-2973, 1990.

RESTLE, J.; ALVES FILHO, D.C.; NEUMANN, M. Eficiência na terminação de bovinos de corte. In: RESTLE, J. (Ed.). Eficiência na produção de bovinos de corte. Santa Maria: Universidade Federal de Santa Maria, 2000. p.277-303.

RESTLE, J.; FATURI, C.; PASCOAL, L.L. Efeito da forma física da aveia preta sobre o desempenho de vacas de descarte terminadas em confinamento. In: REUNIÃO ANUAL DA SOCIEDADE BRASILEIRA DE ZOOTECNIA, 38., 2001, Piracicaba. Anais...Piracicaba: Sociedade Brasileira de Zootecnia, 2001. (CD ROM)

RESTLE, J., VAZ, F.N. Confinamento de bovinos definidos e cruzados. In: LOBATO, J.F.P.; BARCELLOS, J.O.J.; KESSLER, A.M. Produção de bovinos de corte. Porto Alegre: EDIPUCRS, 1999. p.141-168.

SAS INSTITUTE. SAS/STAT Users guide: statistics. 4.ed. 1993. 943p. Version 6, Cary, NC: v.2.

SILVA, N.L.Q. Terminação de novilhos em confinamento alimentados com silagens de dois híbridos de sorgo (Sorghum bicolor L. Moench) associadas a três níveis de concentrado. Santa Maria: Universidade Federal de Santa Maria, 1999. 100p. Dissertação (Mestrado em Zootecnia) Universidade Federal de Santa Maria, 1999.
SILVA, A.V.; PEREIRA, O.G.; VALADARES FILHO, S.C. et al. 2000. Consumo e digestibilidades aparentes total e parcial de nutrientes, em bovinos recebendo rações contendo silagens de milho e sorgo, com e sem inoculante microbiano. In: REUNIÃO ANUAL DA SOCIEDADE BRASILEIRA DEZOOTECNIA, 37., 2000, Viçosa, MG. Anais...Viçosa: Sociedade Brasileira de Zootecnia, 2000. (CD ROM)

STOCK, R.A.; SINDT, M.H.; PARROTT, J.C. et al. Effects of grain type, roughage level and monensin level on finishing cattle performance. Journal of Animal Science, v.68, p.3441-3455, 1990.

TILLEY, J. M.; TERRY, R. A. A two-stage technique for the in vitro digestion of forrage crops. Journal of the British Grassland Society, v.18, p.104-111, 1963.

Van SOEST, P.J.; WINE, R.H. Use of detergents in analysis of fibrous feeds. IV. Determinations of plant cell-wall constituents. Journal of Association Official Analysis Chemists, v.50, p.50, 1967.

VAZ, F.N.; VAZ, R.Z.; ROSO, C. Tipos e níveis de concentrado para confinamento. In: RESTLE, J. (Ed.). Eficiência na produção de bovinos de corte, Santa Maria: Universidade Federal de Santa Maria, 2000. p.219-257.

WALDO, D.R. Symposium: forage utilization by the lactating cow. Effect of forage quality on intake and forage concentrate interactions. Journal of Dairy Science, v.69, p.617-631, 1986.

Recebido em: 14/02/02

Aceito em: 06/11/02 